\section{REQUEST FOR REPRINTS ON CANCER}

To the Editor:-Dr. Angelo Roffo, Saenz Pena 719, Buenos Aires, Argentina, is desirous of obtaining reprints of American literature dealing with experimental and clinical problems concerning cancer. Dr. Roffo is a member of the medical faculty of the University of Buenos Aires, the leader in that country in the study of cancer problems and the representative of the faculty in the new institute now being built for the experimental and clinical study of cancer. Dr. Roffo would appreciate receiving reprints from American writers interested in cancer, and not only would file this literature for the use of workers in the cancer laboratory and hospital but also would abstract it for the Argentine medical weeklies. I am sure he would appreciate any assistance our workers might give him in this connection.

Rrchard M. Pearce, M.D., Philadeiphia.

SIGNS OF FRENCH MAPS AND HIGHWAYS

To the Editor:-Some of the signs used on French maps are unfamiliar to Americans, even though accustomed to reading our own maps. Likewise the highways of France

I Cross $t$ chapelle oSmall church o Large Church
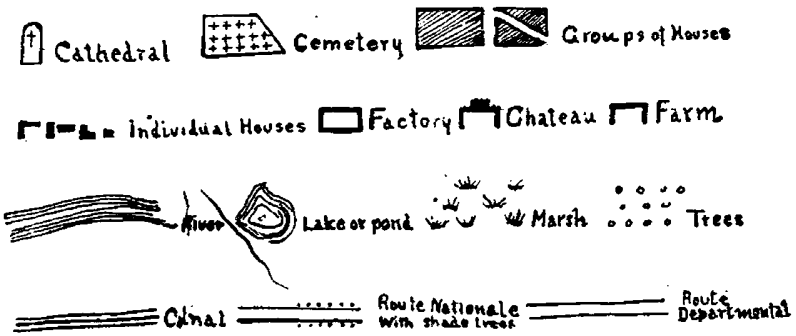

Rode under construet'n
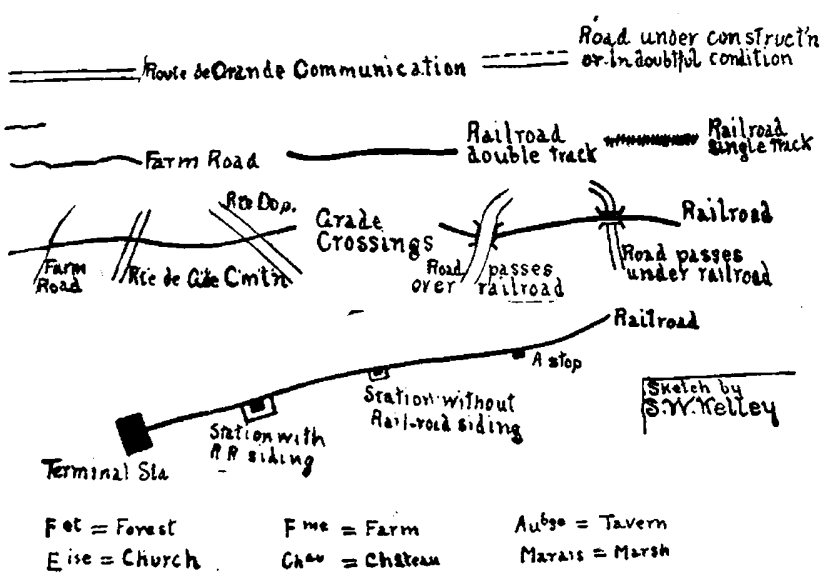

Fig. 1.-Markings and abbreviations in use on French maps.

have indexes and warnings, the meaning of which must be understood to be useful to the traveler. Many American officers and soldiers will be traveling in France in the near

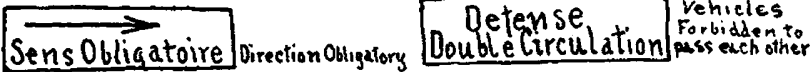

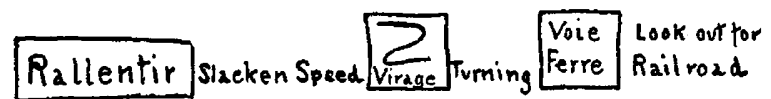

Fig. 2.-Road signs.

future, and in the hope of being useful to them I enclose sketches showing a few of the most ordinary abbreviations, markings and signs which $I$ have found convenient to know in going about the country.

Samuel W. Kelley, M.D., Cleveland. Secteur Postal 205, France.

Chirurgien, Ambulance des Alliés.

\section{BARBARITIES IN MEXICO}

To the Editor:-An interesting side-light on the barbarities practiced by the soldiery of Zapata is shown by a patient who a short time ago entered the United States Marine Hospital here suffering from acute gonorrhea. On examination it was found that the penis had been amputated about one-half inch back of the corona. The patient stated that last year he was a soldier in the Carranzista army, and in a skirmish with some of Zapata's men he was captured and severely tortured. $\mathrm{He}$ was told that he was to be castrated and made to eat his testicles. They finally compromised by offering him death by hanging, with the alternative of having his penis amputated. He chose amputation. The penis was amputated with a saber. He was left to his fate, but happily was picked up by an ambulance driver, who stopped the flow of blood with a bandage.

The patient further stated that he knows of men who have had their ears, nose, tongue and penis amputated by Zapata's men and Villa's men, and portions of these parts forced down the victims' throats.

The stump had evidently received some surgical attention, as the skin of the shaft had been drawn over the raw surface, completely covering it. In the center of the stump was the small orifice of the urethra. The patient stated that erections are less frequent than before the amputation, and the sexual desire is less. He experiences, however, very little difficulty in performing coitus, and has ejaculations. On admission he had a very active acute gonorrhea with an epididymitis.

R. B. ACKÉ, M.D., New Orleans.

Assistant Surgeon, U. S. P. H. S.

\section{THE HANDICAP OF PROPRIETORSHIP IN MEDICINE}

To the Editor:-I am enclosing a reprint of my article on the "Present Status of Pituitary Extract in Labor," which appeared in The Journal, June 2, 1917, p. 1601, and also the September issue of Parke, Davis and Company's Therapeutic Notes, on page 89 of which they quote this article, that you may compare the two. The Therapeutic Notes article is ostensibly a copy, but as a matter of fact, it gives it only in part, which seems to me to be a gross misrepresentation, and one which I do not think should go unnoticed.

Joseph J. Mundell, M.D., Anacostia, D. C.

[Comment.-Therapeutic Notes is one of the house organs of Parke, Davis and Company. A part of each issue is usually devoted to "excerpts" from current literature. The Thcrapeutic Notes may be judged from the manner of "excerpting" the article of Dr. Mundell. Naturally the interest of Parke, Davis and Company is in those sections of the article which may be expected to promote the use of Parke, Davis and Company's proprietary preparation of pituitary extractpituitrin. The following passages from the article of Dr. Mundell were not among those "excerpted" in Therapeutic Notes:

"Used here in properly selected cases, after due consideration by one who has good obstetric judgment, its results are usually happy, and it is a boon to the tired mother and her attendants."

"To step beyond these narrow confines of indications is indeed enter. ing on dangerous territory. Especially is this true as regards the life of the baby. It is recommended in small doses by some good authorities and is frequently used in cases of slight contraction at the brim with sometimes very good results if the birth occurs within a few minutes, but frequently with disastrous results to the baby if delivery is delayed. but frequently with disastrous results to the baby if delivery is delayed.
In such cases, forceps are urgently indicated. Its use in such cases is In such cases, forceps are urgently indicated. Its use in such cases is
risky beyond question. Pituitary extract is recommended in cases of risky beyond question. Pituitary extract is recommended in cases

postpartum hemorrhage, but ergot is undoubtedly to be preferred."

An means shis use should be fully appreciated and due consider and given before its administration in any case, for such a powerful druy used indiscriminately, will surely produce sad results to mother or child

used indi

"During the past two years a number of untoward effects and con sequences of severe character have arisen. As far as the maternal accidents and complications are concerned, I firmly believe that were the slogan of the hour "safety first" borne in mind, a number of them could have been prevented, for beyond question this drug has been greatly abused, as it has been given in too large doses, in cases in which its use was strongly contraindicated, and often, I am sorry to say, for no reason other than the accoucheur's expediency. Its use has beet reckless and careless. The many reports of its rapid and safe action 